\title{
Nucleation and crystallisation kinetics of a Na-fluorrichterite based glass by differential scanning calorimetry (DSC)
}

\author{
J.M. Pérez, R. Casasola, J.Ma. Rincón, M. Romero
}

Group of Glassy and Ceramic Materials, Instituto de Ciencias de la Construcción Eduardo Torroja, CSIC, C/Serrano Galvache, 4. 28033 Madrid, Spain

\begin{abstract}
The present paper shows the results of a nucleation and crystallisation study of a Nafluorrichterite glass carried out by dynamic scanning calorimetry (DSC). The kinetic study was performed using different procedures (Kissinger, Matusita-Sakka and Kissinger-AkahiraSunose (KAS) methods), and the Avrami parameter was determined from the Ozawa and Malek approximations and the Malek equation. The results have indicated the coexistence of surface and bulk crystallisation in the devitrification process of the studied glass. The kinetic study has shown that the activation energy of the crystallisation process is over $400 \mathrm{~kJ} / \mathrm{mol}$ and that the mechanism proposed is a Johnson-Mehl-Avrami mechanism with $\mathrm{n}$ equal to 3, which implies that the crystallisation develops through the three-dimensional growth of crystals. The study of the variation of the activation energy with crystallisation using the KAS method has shown that the crystallisation process undergoes a multiple step mechanism, where the main part of the whole process corresponds to the three-dimensional growth of crystals. The mechanism proposed was confirmed by applying the Pérez-Maqueda et al. criterion.
\end{abstract}

\section{Keywords}

Fluorrichterite; Kinetic; Isoconversional method; Glass-ceramic

\section{Introduction}

Glass-ceramics are materials composed from at least one crystalline and glassy phase, and these materials are produced by a controlled crystallisation process from a base glass. Glassceramics show excellent technological properties, which are usually better than other materials such as glasses, metals or organic polymers [1] because of the wide variety of compositions and microstructures that can be developed. The most critical features for the design of glassceramics are the composition and the microstructure. The crystallisation mechanism of the base 
J.M. Pérez, R. Casasola, J.Ma. Rincón, M. Romero, Nucleation and crystallisation kinetics of a Na-

glass, as well as the chemical and physical properties of the final glass-ceramic, is controlled by the composition, whereas the microstructure is responsible for the mechanical and optical properties.

During the last years of the twentieth century, many studies focused on improving the mechanical strength of glasses and glass-ceramics were conducted. Generally, glasses are tough under compression but weak under tension. In addition, the mechanical strength values that are obtained experimentally for glasses are usually two or three orders of magnitude lower than their theoretical strength. The mechanical weakening of the glass arises from the existence of micro-cracks on the surface. Therefore, the mechanical strength can be increased by generating compressive stresses in the glass surface that neutralise these micro-cracks. Glass strengthening is typically performed via two mechanisms: thermal treatments, such as tempering or quenching, or using a chemical bath, which modifies the chemical composition of the glass surface through ion exchange [2]. Strengthening in glass-ceramics can be achieved from the same surface reinforcement mechanisms that occur in glasses as well as from internal strengthening that occurs from the development of crystals with acicular or rod-like morphologies.

Most glass-ceramics contain silicates as the crystalline phases. In 1991, Beall [3] indicated that inosilicates or chain silicates, which contain single chains based upon $\mathrm{SiO}_{3}{ }^{-}$or double chains based on $\mathrm{Si}_{4} \mathrm{O}_{11}{ }^{-}$, were of great relevance among the crystalline silicates of interest in glass-ceramics because they confer high strength and fracture toughness. Beall evaluated the chain silicate compositions described in the mineralogical literature for their glass-forming nature and ability to devitrify at low pressures. Glass-ceramics, with flexural strengths exceeding $200 \mathrm{MPa}$ and fracture toughness greater than $3 \mathrm{MPa} \cdot \mathrm{m}^{1 / 2}$, were developed using three families of chain silicates: enstatite, potassium fluorrichterite and canasite. Enstatite $\left(\mathrm{MgSiO}_{3}\right)$ is a single chain silicate that is representative of the pyroxene mineral group. Potassium fluorrichterite $\left(\mathrm{KNaCaMg}_{5} \mathrm{Si}_{8} \mathrm{O}_{22} \mathrm{~F}_{2}\right)$ is a double chain silicate that is a member of the amphibole mineral group. Finally, canasite $\left(\mathrm{Ca}_{5} \mathrm{Na}_{4} \mathrm{~K}_{2} \mathrm{Si}_{12} \mathrm{O}_{30} \mathrm{~F}_{4}\right)$ is an unusual quadruple chain silicate.

Following the initial research that was conducted by Beall, the fluorrichterite glass-ceramic has become the subject of great interest and different studies have established the evolution of phases during crystallisation through an early phase separation in the base glass, which first stimulates the crystallisation of tetrasilisic fluormica $\left((\mathrm{K}, \mathrm{Na}) \mathrm{Mg}_{2.5} \mathrm{Si}_{4} \mathrm{O}_{10} \mathrm{~F}_{2}\right)$ at $650{ }^{\circ} \mathrm{C}$ and then diopside $\left(\mathrm{CaMgSi}_{2} \mathrm{O}_{6}\right)$ at $700{ }^{\circ} \mathrm{C}$. The reaction of diopside with mica and the residual glass leads to the development of K-fluorrichterite at $750{ }^{\circ} \mathrm{C}[4]$ and [5]. Different studies have explored the effects of varying magnesium, sodium, silicon or fluorine content on the microstructure and properties of these glass-ceramics [6], [7], [8], [9] and [10] as well as the effects of substituting 
J.M. Pérez, R. Casasola, J.Ma. Rincón, M. Romero, Nucleation and crystallisation kinetics of a Na-

$\mathrm{Na}^{+}$for other alkaline cations $\left(\mathrm{Li}^{+}, \mathrm{K}^{+}\right)[11]$ and [12] or substituting $\mathrm{Mg}^{2+}$ with $\mathrm{Ca}^{2+}[13]$. Furthermore, the effects of $\mathrm{P}_{2} \mathrm{O}_{5}$ on the crystallisation of fluorrichterite have been studied during the last decade because it has been demonstrated that K-fluorrichterite-fluorapatite glassceramics that are formed with different amounts of $\mathrm{P}_{2} \mathrm{O}_{5}$ exhibit excellent in vitro biocompatibility and may be good candidates for bone substitution materials [14], [15] and [16]. Richterite glass-ceramics have also been studied to examine the possibility of producing oriented glass-ceramics with different methods. Therefore, Ashbee [17] has extruded green glasses through opposed dies at temperatures near their respective crystallisation temperatures, and Keding et al. [18] have reported on the use of electrochemical nucleation to induce orientation of the crystals.

In general, the studies mentioned above primarily focused on studying the mineralogical and microstructural features of fluorrichterite glass-ceramics using characterisation techniques such as X-ray diffraction (XRD) or scanning electron microscopy (SEM). However, knowledge of the crystallisation kinetic parameters and the mechanism that governs the devitrification process of fluorrichterite-based glasses is still limited and must be studied further.

Non-isothermal methods are commonly used for the kinetic analysis of solid-state reactions. One of the most employed methods for determining the kinetic parameters of the crystallisation process is the Kissinger method, which was developed to determine the activation energy without having any previous knowledge of the reaction order. For crystal growth studies, the asknown Avrami, or Johnson-Mehl-Avrami model is the most utilised for determining the reaction order of the crystallisation process. Furthermore, isoconversional methods have been used for determining the activation energy as a function of the reacted fraction, and without using any previous assumptions in the kinetic model fitted by the reaction to discern whether a process is multi- or single-step.

The aim of the present work is to obtain the optimum nucleation parameters (temperature and time) and the kinetic parameters (activation energy and reaction mechanism) that are involved in the crystallisation of a Na-fluorrichterite base glass. This study is part of a wide research examining the use of these materials as components in glaze compositions for ceramic tiles. The kinetic study was performed using multi-heating rate procedures (Kissinger and Matusita-Sakka methods) and the isoconversional method of Kissinger-Akahira-Sunose. The $\mathrm{n}$-Avrami parameter was determined from the Ozawa and Malek approximations and Malek equation. The proposed mechanism was confirmed by applying the Pérez-Maqueda et al. criterion. 
J.M. Pérez, R. Casasola, J.Ma. Rincón, M. Romero, Nucleation and crystallisation kinetics of a Nafluorrichterite based glass by differential scanning calorimetry (DSC). Journal of Non-Crystalline Solids Volume 358, Issue 20, 1 October 2012, Pages 2741-2748; doi:10.1016/j.jnoncrysol.2012.05.047

\section{Experimental}

\subsection{Materials and methods}

A parent glass, hereafter designated $\mathrm{R}$ glass, from the $\mathrm{SiO}_{2}-\mathrm{CaO}-\mathrm{MgO}-\mathrm{Na}_{2} \mathrm{O}-\mathrm{F}$ system was prepared from melting a mixture of pure raw materials $\left(53.14 \mathrm{SiO}_{2}, 7.13 \mathrm{CaCO}_{3}, 27.91 \mathrm{MgCO}_{3}\right.$, 7.62 $\mathrm{Na}_{2} \mathrm{CO}$ and $4.20 \mathrm{MgF}_{2}$ (wt.\%)) in an electric oven. The batch was mixed and placed into an alumina-silica crucible, which was subsequently heated at a rate of $10{ }^{\circ} \mathrm{C} / \mathrm{min}$ up to $1450{ }^{\circ} \mathrm{C}$ where the temperature was held for $2 \mathrm{~h}$. The melt was poured into a brass mould to form a glass bar, which was then annealed for $2 \mathrm{~h}$ at $550{ }^{\circ} \mathrm{C}$ to avoid internal stresses. The annealing temperature was chosen to be $100{ }^{\circ} \mathrm{C}$ lower than glass transition temperature $\left(\mathrm{T}_{\mathrm{g}}\right)$ determined from the results of differential scanning calorimetry (DSC) conducted previously on a sample of glass with the same composition. The chemical analysis of the resulting glass was determined by X-ray fluorescence (XRF), and to verify the glass was in an amorphous state, the as-annealed glass was analysed using X-ray diffraction (XRD).

The crystallisation behaviour was determined by DSC on two samples of different particle sizes: a fine sample of glass powder that was ground and sieved to a particle size $<63 \mu \mathrm{m}$ and a coarse sample obtained from cutting the glass bar into monolithic samples $(2 \times 2 \times 3 \mathrm{~mm})$. DSC tests were performed using a SETARAM Labsys Thermal Analyzer. The samples were placed into platinum crucibles and calcined $\mathrm{Al}_{2} \mathrm{O}_{3}$ was used as reference material. The temperature precision given by the thermal analyzer is $\pm 0.1^{\circ} \mathrm{C}$. To evaluate the crystalline phases that developed during crystallisation, both samples of different particle sizes were subjected to a thermal treatment for $1 \mathrm{~h}$ at a temperature that was slightly greater than the $\mathrm{Tp}$, which is the temperature at the maximum of the crystallisation peak. XRD patterns were collected from powdered samples using $\mathrm{Ni}$-filtered $\mathrm{CuK} \alpha$ radiation on a Philips $\mathrm{X}$-ray diffractometer operating at $30 \mathrm{~mA}$ and $50 \mathrm{kV}$. The scanning speed was set at $2 \theta / \mathrm{min}$ with time per step of $0.02 \mathrm{~s}$. Phase identification was performed using the International Centre for Diffraction Data (PDF) database [19]. To better understand the crystallisation sequence that takes place during the devitrification process of $\mathrm{R}$ glass, bulk samples were crystallised for 60 min over $860-920{ }^{\circ} \mathrm{C}$, and their microstructure was observed using field emission scanning electron microscopy (FESEM) in a HITACHI S-4800P microscope using an acceleration voltage of $20 \mathrm{kV}$. FESEM specimens were polished to $1 \mu \mathrm{m}$ finish using diamond pastes following initial grinding with $\mathrm{SiC}$ powder. The samples were subsequently etched for $10 \mathrm{~s}$ in a solution of $5 \% \mathrm{HF}$, ultrasonically washed with distilled water and ethylic alcohol, dried and then coated with $\mathrm{Au}-$ Pd in a Balzers SCD 050 sputter. 
J.M. Pérez, R. Casasola, J.Ma. Rincón, M. Romero, Nucleation and crystallisation kinetics of a Na-

The optimum nucleation parameters (time and temperature) were determined for the monolithic glass samples using a two-step experiment consisting of a first isothermal step at different nucleation temperatures followed by a dynamic (non-isothermal) step until crystallisation is completed, which is detected by the completion of the exothermic crystallisation peak in the DSC curve. The heating rate, $\beta$, must fulfil the condition that no new nuclei may be formed during crystallisation. This condition is accomplished using high heating rates (unless $10^{\circ} \mathrm{C} / \mathrm{min}$ ) from the nucleation step to the final crystallisation process. It is important to remember that it is preferable to obtain the nucleation parameters from coarse samples, because nucleation must be avoided to be a function of the surface of particles. During the isothermal step, the samples were heated in the DSC at a rate of $50^{\circ} \mathrm{C} / \mathrm{min}$ from room temperature up to a temperature range around the $\mathrm{T}_{\mathrm{g}}\left(600-700^{\circ} \mathrm{C}\right)$ and then kept at the chosen temperature for $15 \mathrm{~min}$; subsequently, the samples were heated using the same heating rate up to $1400{ }^{\circ} \mathrm{C}$. The plot of the inverse of the temperature at the maximum of the crystallisation peak $\left(T_{p}\right)$ versus the nucleation temperature allows the determination of the optimum nucleation temperature $\left(\mathrm{T}_{\mathrm{N}}\right)$ as the maximum of the curve.

Once the optimum temperature was fixed, the optimum nucleation time $\left(t_{N}\right)$ was determined using a similar test sequence where the glass samples were subjected to an isothermal step at $\mathrm{T}_{\mathrm{N}}$ for different times $(15-160 \mathrm{~min})$. Similarly, the plot of the inverse of $\mathrm{T}_{\mathrm{p}}$ versus the nucleation time gives the optimum nucleation time as the onset of a plateau in the curve. The method described, including non-isothermal steps, is based on the reasonable assumption that the inverse of the crystallisation peak $\left(1 / \mathrm{T}_{\mathrm{p}}\right)$ is proportional to the density of nuclei that are formed during the nucleation stage.

The crystallisation kinetic study examined monolithic glass samples using the conditions that were determined from the nucleation study, by varying the heating rate $(10,20,30,40$ and $50 \mathrm{~K} \mathrm{~min}^{-1}$ ) from the nucleation temperature to $1200{ }^{\circ} \mathrm{C}$. Each measurement was reproduced three times in order to estimate experimental errors.

\subsection{Theory}

To study the crystallisation kinetics, values of the activation energy $\left(E_{a}\right)$, pre-exponential factor $\left(\mathrm{k}_{0}\right)$ and mechanism ( $\mathrm{f}(\alpha)$ ) of the process were calculated by applying non-isothermal methods. For non-isothermal data, the reaction rate equation is expressed as:

$$
\frac{d \alpha}{d t}=\beta \cdot \frac{d \alpha}{d T}=k_{0} \cdot f(\alpha) \cdot \exp \left(\frac{-E_{a}}{R \cdot T}\right)
$$


J.M. Pérez, R. Casasola, J.Ma. Rincón, M. Romero, Nucleation and crystallisation kinetics of a Na-

where $\alpha$ is the extent of the reaction, $\beta$ is the heating rate $(\mathrm{K} / \mathrm{min}), \mathrm{T}$ is the temperature and $\mathrm{R}$ is the gas constant.

The Johnson-Mehl-Avrami (JMA) mechanism is typically used for crystallisation [20],[21] and [22], which is expressed in the differential form as:

$$
f(\alpha)=n \cdot(1-\alpha) \cdot[-\operatorname{Ln}(1-\alpha)]^{1-1 / n}
$$

where $\mathrm{n}$ is the Avrami exponent, which is associated to the morphology of crystal growth.

By developing Eq. (1) and taking the logarithms, the activation energy can be obtained by applying the Kissinger method [23]:

$$
\operatorname{Ln}\left(\frac{\beta}{T_{p}^{2}}\right)=\operatorname{cte}-\frac{E_{a}}{R \cdot T_{p}}
$$

where $T_{p}$ is the temperature at the maximum of the exothermic peak and cte is a constant.

Matusita and Sakka [24] have proposed another equation when the number of nuclei is influenced by the heating rate.

$$
\operatorname{Ln}\left(\frac{\beta^{n}}{T_{p}^{2}}\right)=\operatorname{cte}-\frac{m \cdot E_{a}}{R \cdot T_{p}}
$$

If the value of $m$ is equal to $n$, it is indicated that the sample is well nucleated and that there are no new nuclei formed during the crystallisation process; whereas if $\mathrm{n} \neq \mathrm{m}$, it is indicated that new nuclei are developed during crystallisation.

The Avrami parameter, $\mathrm{n}$, can be determined from the equation proposed by Ozawa [25]:

$$
\left.\frac{d[\operatorname{Ln}(-\operatorname{Ln}(1-\alpha))]}{\mathrm{d}(\operatorname{Ln} \beta)}\right|_{\mathrm{T}}=-\mathbf{n}
$$

where $\alpha$ is estimated by evaluating the partial area of the crystallisation peak from exotherms that are obtained at different heating rates at a fixed temperature, $\mathrm{T}$.

The value of $\mathrm{n}$ can also be determined from the relation proposed by Malek [26] (hereafter designed as Malek approximation) in the following form: 


$$
\left.\frac{d \operatorname{Ln}[-\operatorname{Ln}(1-\alpha)]}{\mathrm{d}\left(\frac{1}{\mathrm{~T}}\right)}\right|_{\beta} \cong-\frac{\mathrm{n} \cdot \mathrm{E}_{\mathrm{a} \alpha}}{\mathrm{R}}
$$

where $\mathrm{E}_{\mathrm{a} \alpha}$ is the activation energy that is obtained from the isoconversional method, as explained below.

Further evaluation of $n$ can be achieved from the plot of $f(\alpha)$ versus $\alpha$. The value of $n$ is determined from the maximum of curve $\left(\alpha_{M}\right)$ using the equation proposed by Malek [26](hereafter designed as Malek equation):

$$
\alpha_{M}=1-\exp \left(\frac{1-n}{n}\right)
$$

The isoconversional method that is employed in this work is based on dynamic DSC analyses. The equation for the reaction rate, which is employed to study the degree of crystallisation, can be expressed by Eq. (1). Considering that the rate equation (Eq. 1 ) is valid for dynamic process, the rate equation can be expressed in its integral form as:

$$
\mathrm{g}(\alpha)=\int_{0}^{\alpha} \frac{d \alpha}{\mathrm{f}(\alpha)}=\frac{\mathrm{k}_{0}}{\beta} \int_{0}^{\mathrm{T}} \mathrm{e}^{\left(\mathrm{E}_{\alpha \alpha / \mathrm{k}} \cdot \mathrm{T}\right)} d \mathrm{~T}
$$

Using the Murray and White approximation [27] of the temperature integral, the following equation is obtained:

$$
\operatorname{Ln}\left(\frac{\beta}{T_{p}^{2}}\right)=\operatorname{Ln}\left(\frac{R \cdot k_{0}}{E_{\alpha \alpha} \cdot g(\alpha)}\right)-\frac{E_{\alpha \alpha}}{R} \cdot \frac{1}{T_{p}}
$$

where $T_{\alpha}$ is the temperature of a fixed degree of crystallisation. Eq. (9) is known as the Kissinger-Akahira-Sunose (KAS) [28] model-free method that can be applied to different degrees of conversion. According to Eq. (9), the activation energy and the pre-exponential factor can be calculated using the slope and the ordinate values expressed by the linear relationship between $\operatorname{Ln} \beta / \mathrm{T}_{\alpha}{ }^{2}$ and $1 / \mathrm{T}_{\alpha}$.

This method does not require knowledge of the conversion-dependent function $(f(\alpha)$ or $g(\alpha)$ ), and the only assumption is that the process follows the same reaction mechanism for a given degree of conversion, regardless of the crystallisation temperature.

The appropriate conversion function can be discriminated by applying the Pérez-Maqueda et al. criterion [29], who have drawn the lines $\operatorname{Ln}[\beta(\mathrm{d} \alpha / \mathrm{dT}) / \mathrm{f}(\alpha)]$ versus $1 / \mathrm{T}$ for a set of conversion functions and for all heating rates. A given conversion function corresponds to one of the 
J.M. Pérez, R. Casasola, J.Ma. Rincón, M. Romero, Nucleation and crystallisation kinetics of a Na-

following family of curves: (a) non-linear curves; (b) linear curves (parallels) but with the intercept dependent upon the heating rate, and (c) a single line for all heating rates. The real conversion function corresponds to case (c), a single line for all heating rates. In the present paper, and according to Mocioiu et al. [30] and Cadenato et al. [31], the conversion function is determined from the plots of $\operatorname{Ln}\left[\beta\left(g(\alpha) / T^{2}\right]\right.$ versus $(1 / T)$ for the different heating rates.

The kinetic schedule that was followed was first the application of the non-isothermal Kissinger method for the determination of the activation energy, and the Avrami parameter was subsequently determined from the Ozawa and Malek approximations and from the Malek equation. The Matusita-Sakka method was applied using these parameters to obtain the $\mathrm{m}$ value. Then, the isoconversional Kissinger-Akahira-Sunose method was used to understand the multiple mechanisms and their meaning. Finally, the results were contrasted using the PérezMaqueda criterion to test the feasibility of the proposed Avrami mechanism.

\section{Results}

Table 1 shows the results from the chemical analysis of the investigated $\mathrm{R}$ glass, which is located in the $\mathrm{SiO}_{2}$-rich part of the ternary $\mathrm{SiO}_{2}-\mathrm{MgO}-\mathrm{CaO}$ glass formation system (Fig. 1).Fig. 2 shows the XRD pattern from a powdered sample of the as-annealed R glass. The absence of relevant diffraction peaks, along with the presence of the typical wide band that corresponds to the glassy matrix (amorphous halo), indicates the complete amorphous state of the sample.

Table 1. Chemical analysis of $\mathrm{R}$ glass determined by XRF.

\begin{tabular}{|ll|}
\hline Component & wt.\% \\
\hline $\mathrm{SiO}_{2}$ & $57.49 \pm 0.09$ \\
$\mathrm{Al}_{2} \mathrm{O}_{3}$ & $5.31 \pm 0.03$ \\
$\mathrm{MgO}$ & $20.82 \pm 0.05$ \\
$\mathrm{CaO}$ & $7.81 \pm 0.02$ \\
$\mathrm{Na} 2 \mathrm{O}$ & $6.13 \pm 0.04$ \\
$\mathrm{~K}_{2} \mathrm{O}$ & $0.32 \pm 0.01$ \\
$\mathrm{~F}_{2}$ & $2.11 \pm 0.10$ \\
\hline
\end{tabular}




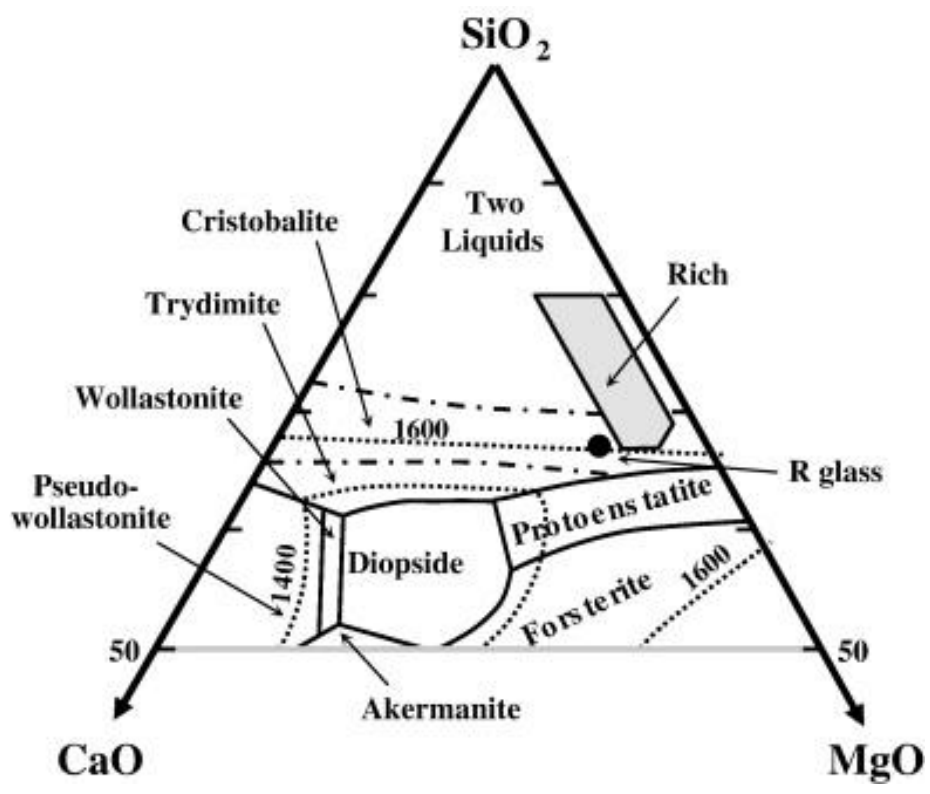

Fig. 1. Phase diagram of the $\mathrm{SiO}_{2}-\mathrm{MgO}-\mathrm{CaO}$ system.

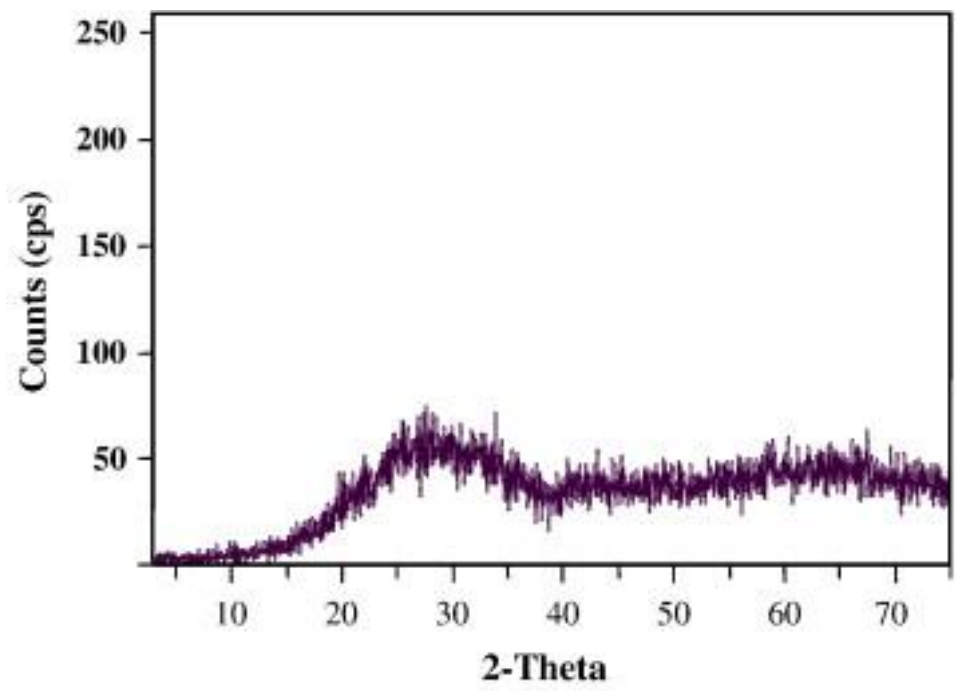

Fig. 2. X-ray diffraction pattern of the annealed R glass sample.

Fig. 3 presents the DSC thermograms from fine $(<63 \mu \mathrm{m})$ and coarse samples obtained from the $\mathrm{R}$ glass. The first endothermic jump in the baseline of the thermograms corresponds to the 
J.M. Pérez, R. Casasola, J.Ma. Rincón, M. Romero, Nucleation and crystallisation kinetics of a Na-

glass transition temperature $\left(\mathrm{T}_{\mathrm{g}}\right)$, which appears at $647{ }^{\circ} \mathrm{C}$ in both curves. Just after the endothermic effect associated with the $\mathrm{T}_{\mathrm{g}}$, the DSC curves show a slight endothermic drop (a detailed view is also shown in Fig. 3). The detailed box also depicts the typical shape of a DSC curve around the $\mathrm{T}_{\mathrm{g}}$ of a quenched glass without further annealing (dotted line). The $\mathrm{R}$ glass curves show an endothermic descent below the dotted line that indicates an enthalpic relaxation process. Both curves show a well-defined exothermic peak that corresponds to a crystallisation process. However, the temperatures at the onset and at the maximum of the crystallisation peak shift with the size of the glass particle. The fine sample shows the crystallisation process occurring at lower temperatures and with higher intensity than the coarse sample. Once the crystallisation peak is completed, the temperature increase induces an endothermic process with a minimum $\left(\mathrm{T}_{\mathrm{m}}\right)$ at 1171 and $1192{ }^{\circ} \mathrm{C}$ for the fine and coarse samples, respectively, which is indicative of the melting of the main crystalline phases that formed during heating.

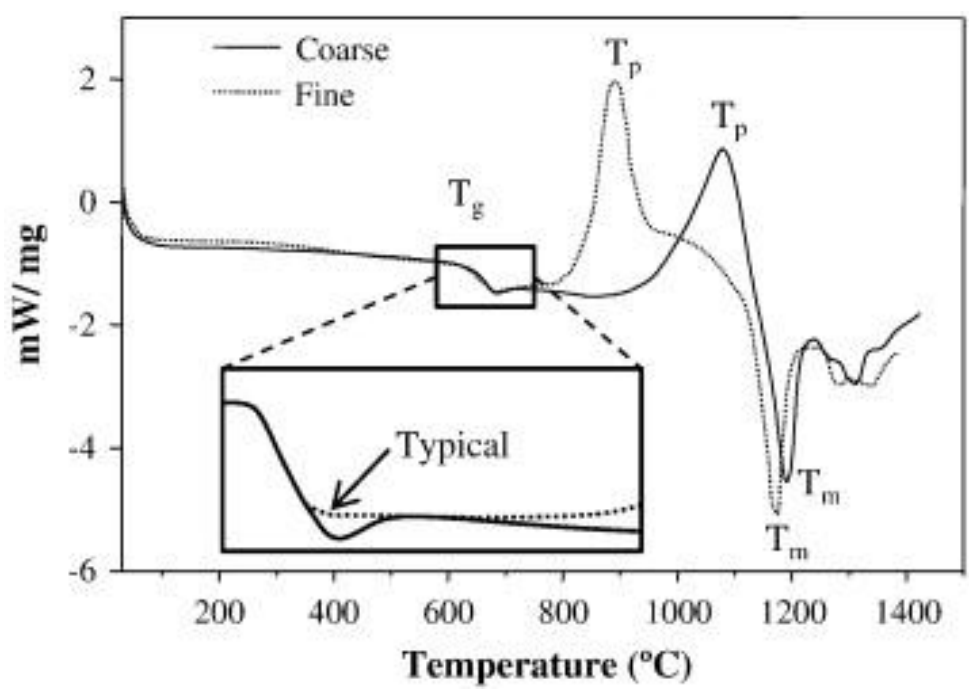

Fig. 3. DSC thermograms for fine (\&1t; $63 \mu \mathrm{m}$ ) and coarse (monolithic) samples recorded at $50{ }^{\circ} \mathrm{C} / \mathrm{min}$.

To evaluate the crystalline phases that developed during the crystallisation process, both samples were subjected to a thermal treatment for $1 \mathrm{~h}$ at a temperature that was slightly above the temperature at the maximum of their crystallisation peaks. The temperatures chosen were $950{ }^{\circ} \mathrm{C}$ and $1100{ }^{\circ} \mathrm{C}$ for the fine and coarse samples, respectively. Fig. 4shows the XRD patterns of the crystallised glass samples. The same crystalline phases are identified in both samples, specifically, fluorrichterite $\left(\mathrm{Na}_{2} \mathrm{CaMg}_{5} \mathrm{Si}_{8} \mathrm{O}_{22} \mathrm{~F}_{2}\right)$, diopside $\left(\mathrm{CaMgSi}_{2} \mathrm{O}_{6}\right)$ and a magnesium 
silicate. However, the relative amounts of the different phases vary depending on the particle size of the glass. Fluorrichterite is the main crystalline phase that developed in the coarse sample, whereas diopside is the main crystalline phase in the fine sample. As for magnesium silicate, forsterite $\left(\mathrm{Mg}_{2} \mathrm{SiO}_{4}\right)$ and enstatite $\left(\mathrm{MgSiO}_{3}\right)$ appear as minor phases in the fine and coarse samples, respectively.
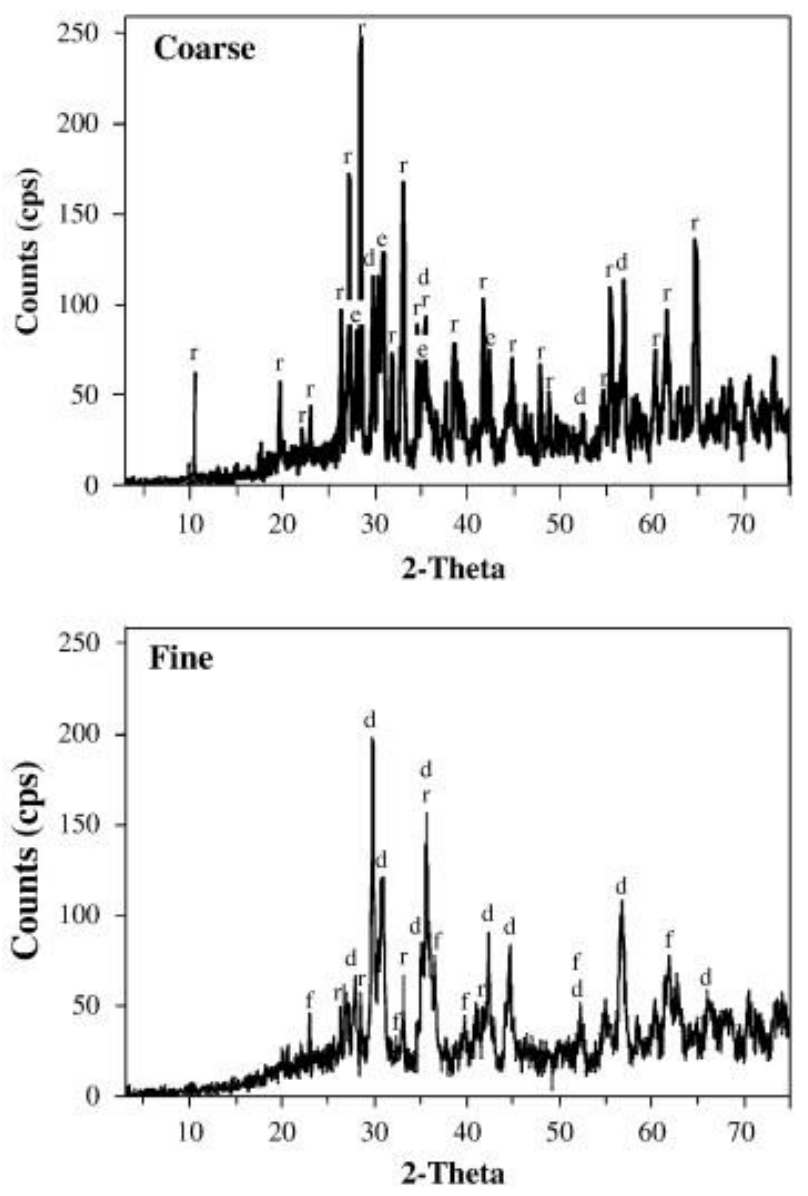

Fig. 4. X-ray diffraction patterns for a coarse glass sample heat treated at $1100{ }^{\circ} \mathrm{C}$ for $1 \mathrm{~h}$, and a fine glass sample heat treated at $950{ }^{\circ} \mathrm{C}$ for $1 \mathrm{~h}(\mathrm{r}=$ fluorrichterite, $\mathrm{d}=$ diopside, $\mathrm{e}=$ enstatite and $\mathrm{f}=$ forsterite) .

As shown in Fig. 5, the optimum nucleation temperature is $675^{\circ} \mathrm{C}$ as obtained from the plot of the inverse of the temperature at the maximum of the crystallisation peak versus nucleation temperature in the coarse (monolithic) glass sample. Fig. 6 shows the variation of $\left(1 / \mathrm{T}_{\mathrm{p}}\right)$ with 
J.M. Pérez, R. Casasola, J.Ma. Rincón, M. Romero, Nucleation and crystallisation kinetics of a Na-

nucleation time in monolithic samples that were nucleated at $675{ }^{\circ} \mathrm{C}$. The onset of the plateau (80 $\mathrm{min})$ in the plot indicates the optimum nucleation time.

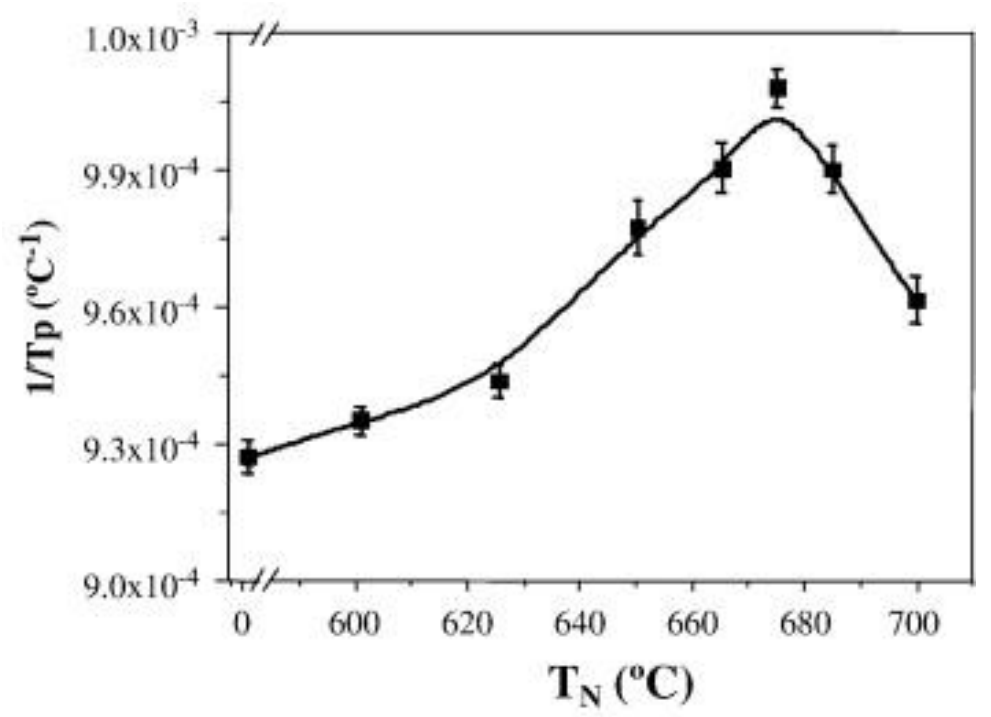

Fig. 5. Plot of the inverse of the temperature at the maximum of the crystallisation peak (Tp) vs. the nucleation temperature for glass samples nucleated for $15 \mathrm{~min}$. Lines are drawn to guide the eyes.

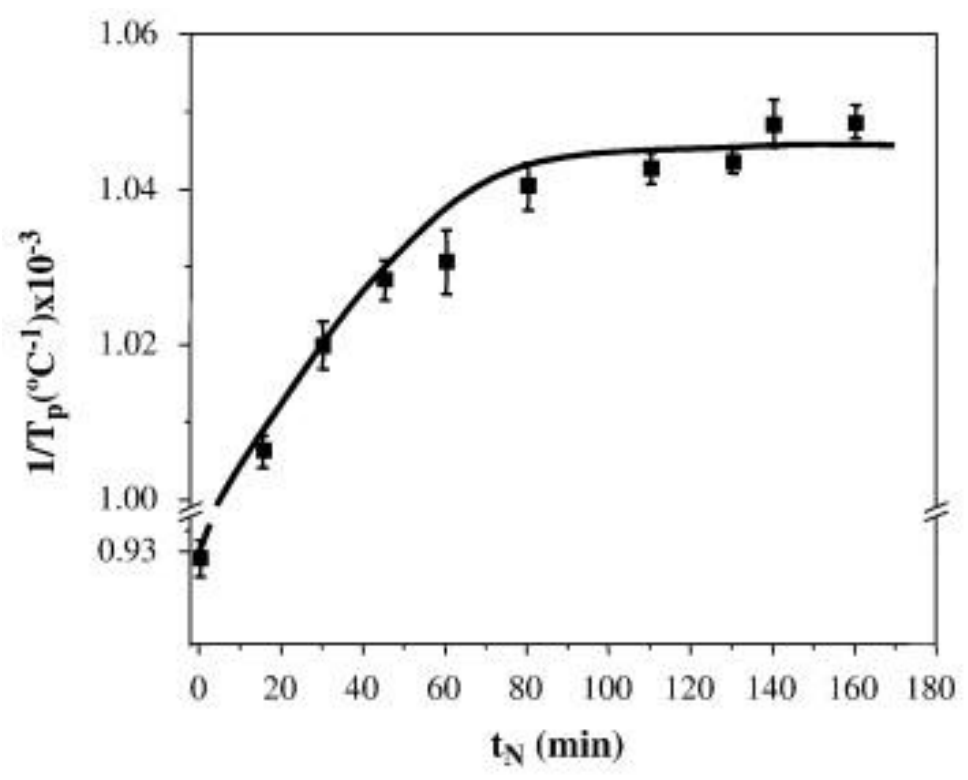

Fig. 6. Plot of the inverse of the temperature at the maximum of the crystallisation peak (Tp) vs. nucleation time for glass samples nucleated at $675^{\circ} \mathrm{C}$. Lines are drawn to guide the eyes. 
To better understand the crystallisation sequence that occurs during the devitrification process of the $\mathrm{R}$ glass, bulk samples were crystallised for 60 min at temperatures of 860, 880, 900 and $920^{\circ} \mathrm{C}$. Fig. 7 shows the microstructure observed by FESEM in the heat-treated samples.
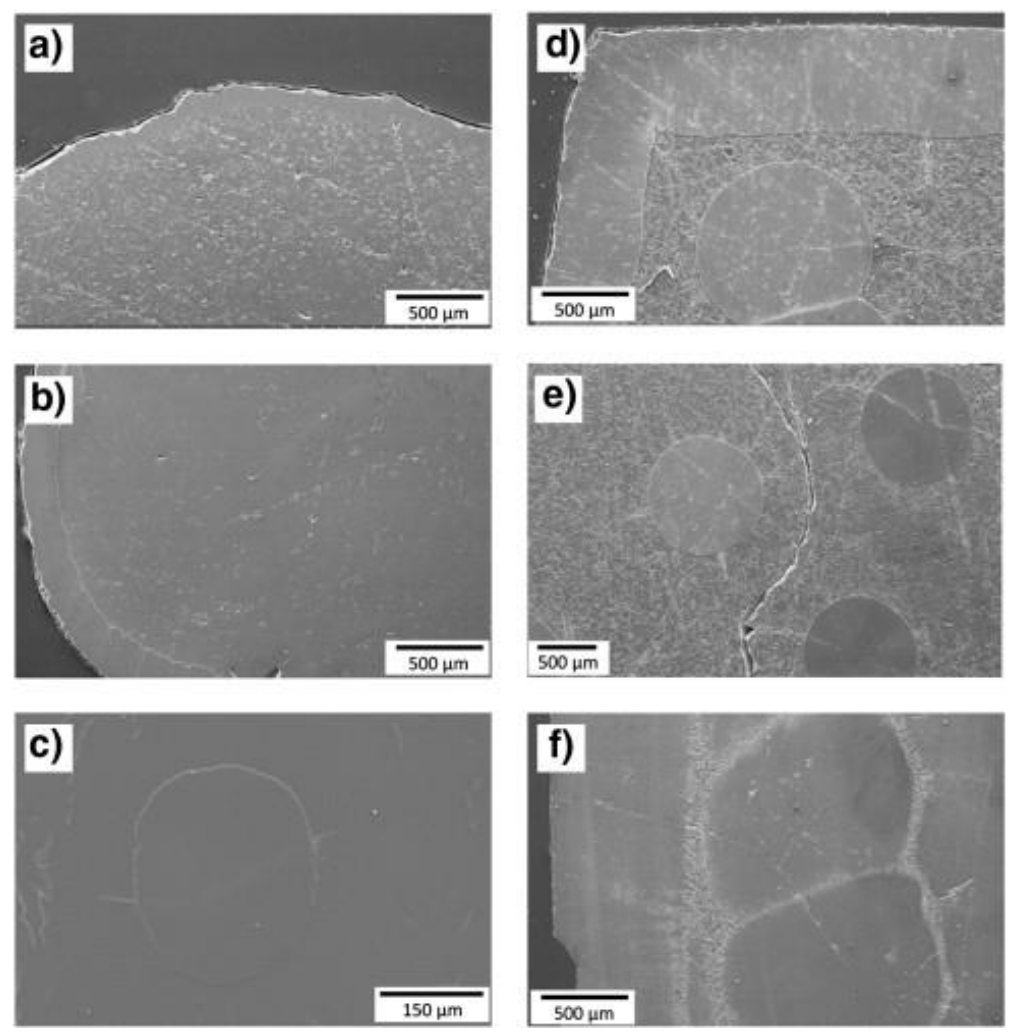

Fig. 7. FESEM micrographs of R glass samples heat treated for 60 min at a) $860{ }^{\circ} \mathrm{C}$; b) and c) $880{ }^{\circ} \mathrm{C} ;$ d) and e) $900{ }^{\circ} \mathrm{C} ;$ f) $920^{\circ} \mathrm{C}$.

The activation energy for the crystallisation was determined using the Kissinger method (Eq. 3) on both fine $(<63 \mu \mathrm{m})$ and nucleated monolithic samples (Fig. 8). The value of the activation energy $\left(E_{a}\right)$, as determined from the slope of the plot of $\operatorname{Ln}\left(\beta / T_{p}^{2}\right)$ versus $\left(1 / T_{p}\right)$, was $440 \pm 18$ and $401 \pm 22$ for the fine and coarse samples, respectively.

Table 2 presents the Avrami exponents determined by applying the Ozawa Eq. (5) and Malek Eq. (6) approximations to the nucleated monolithic samples. Temperatures of 1165, 1190 and $1200 \mathrm{~K}$ were chosen for the Ozawa approximation. These values are very close to each other because the condition $0<\alpha<1$ for all heating rates is only satisfied over the $1158-1208 \mathrm{~K}$ interval. The values of $n$, as determined from the slope of the plot of $d \operatorname{Ln}[-\operatorname{Ln}(1-\alpha)]$ versus $(1 / \mathrm{T})$ at different heating rates (Malek approximation, Eq. 6), are in the interval 2.59- 
J.M. Pérez, R. Casasola, J.Ma. Rincón, M. Romero, Nucleation and crystallisation kinetics of a Na-

3.57. Fig. 9 depicts the Malek curves that were obtained for different heating rates. All curves show a similar shape, which indicates that the crystallisation process follows a single reaction mechanism, regardless of the heating rate [32]. The values of $n$ as determined by applying $\alpha_{M}$ in the Malek equation (Eq. 7) are also shown in Table 2.

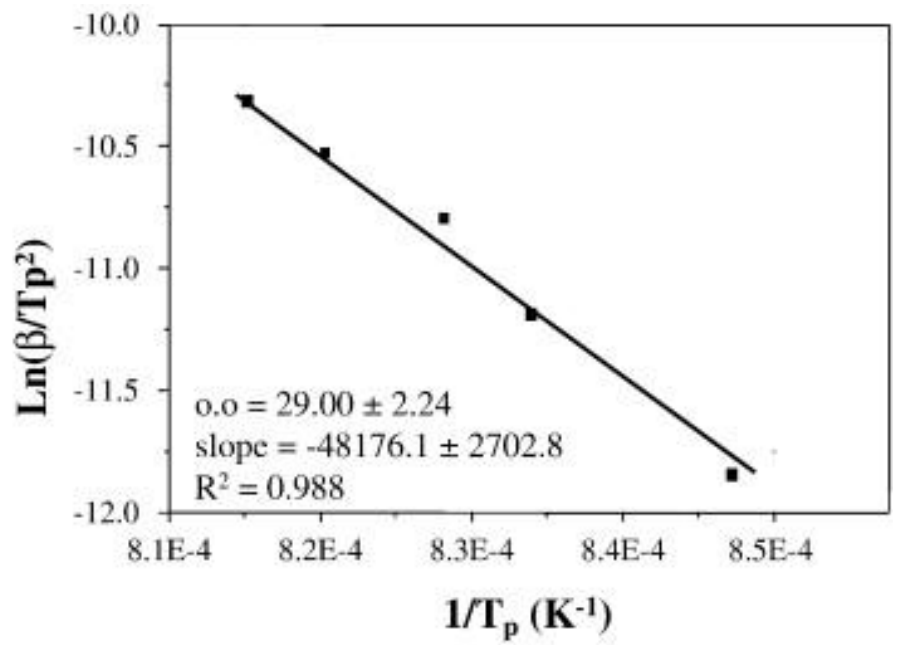

Fig. 8. Kissinger plot for $\mathrm{R}$ glass nucleated at $675^{\circ} \mathrm{C}$ for $80 \mathrm{~min}$. Line represents the least square fitting through the data points.

Table 2. Values of n Avrami parameter determined from Ozawa (Eq. (5)) and Malek (Eq. (6)) approximations and Malek equation (Eq. (7)).

\begin{tabular}{|c|c|c|c|c|c|}
\hline \multicolumn{2}{|c|}{ Ozawa approximation } & \multirow[t]{2}{*}{$\beta(\mathrm{K} / \mathrm{min})$} & Malek method & \multicolumn{2}{|l|}{ Malek plot } \\
\hline $\mathrm{T}(\mathrm{K})$ & $\mathrm{n} \pm \Delta \mathrm{n}^{\mathrm{a}}$ & & $\mathrm{n} \pm \Delta \mathrm{n}^{\mathrm{a}}$ & $\alpha \max \pm \Delta \alpha \max ^{\mathrm{a}}$ & $\mathrm{n} \pm \Delta \mathrm{n}^{\mathrm{a}}$ \\
\hline 1165 & $3.03 \pm 0.41$ & 10 & $3.41 \pm 0.09$ & $0.48 \pm 0.02$ & $2.91 \pm 0.33$ \\
\hline 1190 & $2.87 \pm 0.22$ & 20 & $2.59 \pm 0.16$ & $0.50 \pm 0.01$ & $3.30 \pm 0.19$ \\
\hline \multirow[t]{4}{*}{1200} & $2.84 \pm 0.28$ & 30 & $2.69 \pm 0.17$ & $0.44 \pm 0.03$ & $2.42 \pm 0.36$ \\
\hline & & 40 & $3.39 \pm 0.19$ & $0.47 \pm 0.03$ & $2.78 \pm 0.33$ \\
\hline & & 50 & $3.57 \pm 0.18$ & $0.50 \pm 0.02$ & $3.26 \pm 0.43$ \\
\hline & & Average & $3.19 \pm 0.38$ & $2.94 \pm 0.36$ & \\
\hline Standar & iation. & & & & \\
\hline
\end{tabular}


J.M. Pérez, R. Casasola, J.Ma. Rincón, M. Romero, Nucleation and crystallisation kinetics of a Na-

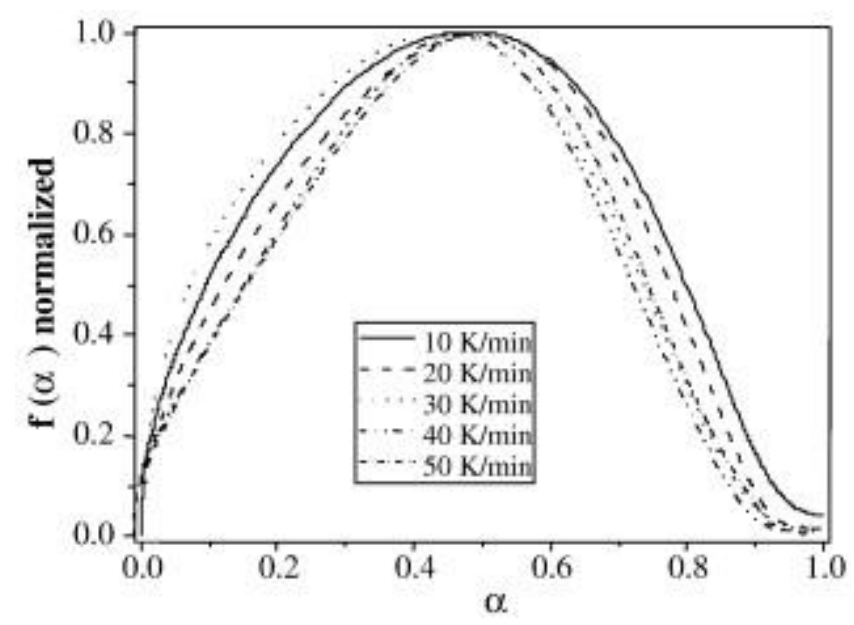

Fig. 9. Malek curves obtained for different heating rates.

Fig. 10 shows the variation of $E_{a \alpha}$ with the degree of conversion, $\alpha$, as determined with the KAS isoconversional method (Eq. 9). The plot depicts three reaction steps during the crystallisation process, an increase in $\mathrm{E}_{\mathrm{a} a}$ at lower conversion degrees, constant $\mathrm{E}_{\mathrm{a} \alpha}(\approx 389 \pm 7 \mathrm{~kJ} / \mathrm{mol})$ in the interval $\alpha=0.2-0.8$, and finally, a decrease in the activation energy from $\alpha=0.8$ to the end of the reaction.

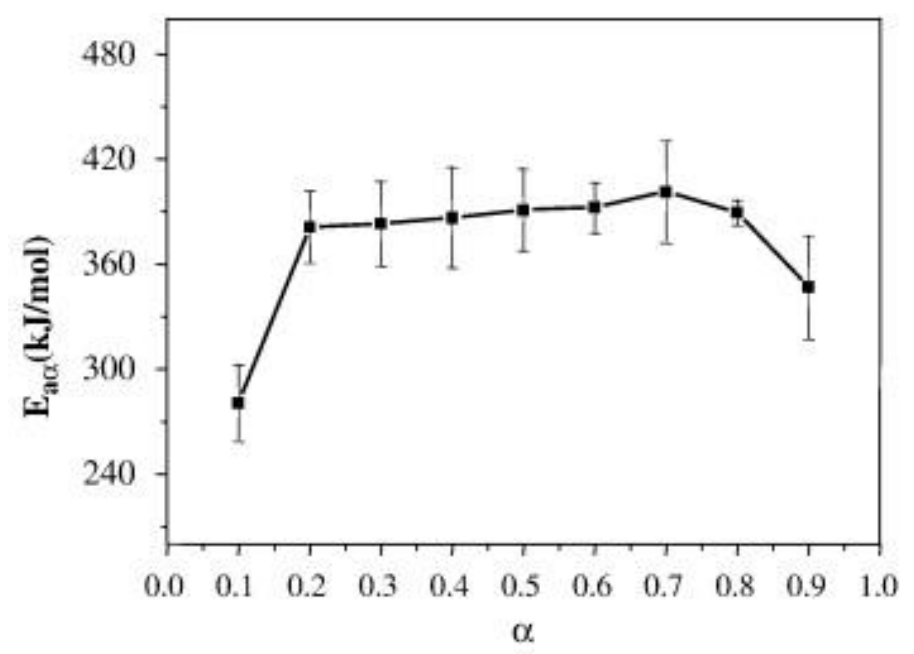

Fig. 10. Plot of the isoconversional activation energy vs. the conversion degree $(\alpha)$ determined by the Kissinger-Akahira-Sunose method. Lines are drawn to guide the eyes. 
To evaluate the accuracy of the proposed crystallisation mechanism $(n=3)$, the PérezMaqueda et al. criterion was applied over the interval of conversion $\alpha=0.2-0.8$, where the activation energy that was obtained using the KAS isoconversional method is constant.Fig. 11 shows the plots of $\operatorname{Ln}[\beta(\mathrm{d} \alpha / \mathrm{dT}) / \mathrm{f}(\alpha)]$ versus $1 / \mathrm{T}$ for different $\mathrm{A}_{\mathrm{n}}$ mechanisms ( $n=2,2 / 3,3$ and 4). According to Pérez-Maqueda et al., the correct kinetic model is that which shows kinetic parameters that are independent of the heating rate. The plots for the $A_{2}, A_{2 / 3}$ and $\mathrm{A}_{4}$ mechanisms lead to a family of lines with similar slopes, but different y-intercepts. Nevertheless, the lines corresponding to the plot of the $\mathrm{A}_{3}$ model fit a straight line, indicating that the crystallisation process proceeds through a three dimensional growth of crystals.
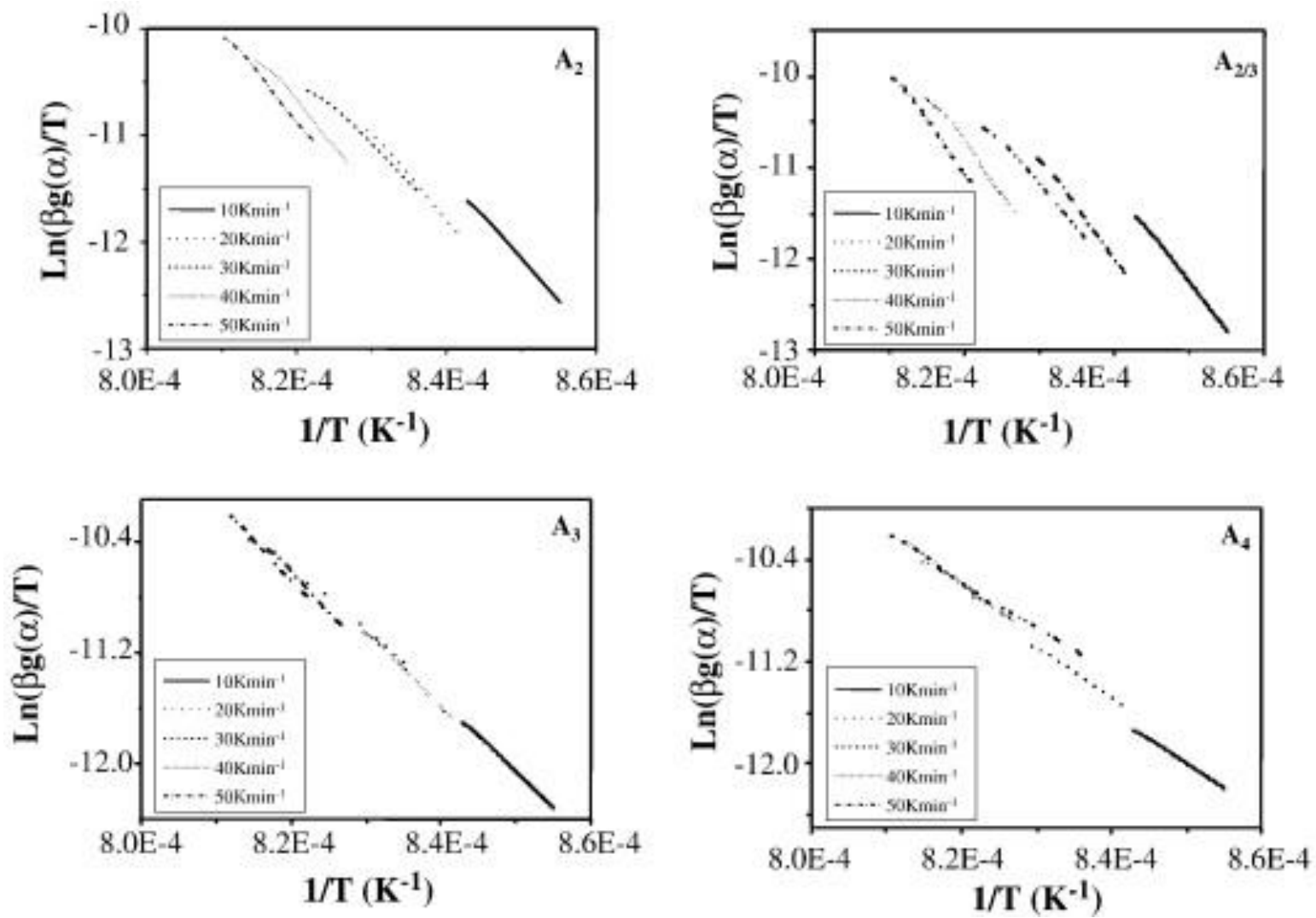

Fig. 11. Perez-Maqueda plot of $\operatorname{Ln}(\beta g(\alpha) \cdot T-2)$ vs. $T-1$, for different An mechanisms: A2, A2/3, A3 and A4.

\section{Discussion}

The chemical composition of the $\mathrm{R}$ glass is located in the $\mathrm{SiO}_{2}$-rich part of the ternary $\mathrm{SiO}_{2}-$ $\mathrm{MgO}-\mathrm{CaO}$ glass formation system (Fig. 1). However, Beall [3] reported that the incorporation 
J.M. Pérez, R. Casasola, J.Ma. Rincón, M. Romero, Nucleation and crystallisation kinetics of a Nafluorrichterite based glass by differential scanning calorimetry (DSC). Journal of Non-Crystalline Solids Volume 358, Issue 20, 1 October 2012, Pages 2741-2748; doi:10.1016/j.jnoncrysol.2012.05.047

of fluorine and alkali ions into the glass composition considerably modifies the ternary system and that crystalline phases can be developed that are not expected in a simple $\mathrm{SiO}_{2}-\mathrm{MgO}-\mathrm{CaO}$ system. The analysed $\mathrm{R}$ glass composition is very close to the composition of 55-70 $\mathrm{SiO}_{2}, 10$ $25 \mathrm{MgO}, 2-6 \mathrm{CaO}, 2-6 \mathrm{Na}_{2} \mathrm{O}, 2-7 \mathrm{~K}_{2} \mathrm{O}$, and 2-5 F (labelled as Rich in Fig. 1), which leads to the devitrification of the richterite chain silicate [1]. Indeed, the $\mathrm{T}_{\mathrm{g}}$ value of the $\mathrm{R}$ glass $\left(647{ }^{\circ} \mathrm{C}\right)$ is similar to the value of $\mathrm{T}_{\mathrm{g}}=635^{\circ} \mathrm{C}$ that was reported by Hamzawy and AbdelHameed [11] for a glass with a stoechiometric fluorrichterite composition. Moreover, the temperature at the maximum of the crystallisation peak is 891 and $1080{ }^{\circ} \mathrm{C}$ for fine and coarse samples, respectively, which are in agreement with the values reported in the literature for glasses with the stoechiometric composition of fluorrichterite [11] and [18]. The crystallisation of fluorrichterite from the $\mathrm{R}$ parent glass has been also verified in Fig. 4, which shows that fluorrichterite is the main crystalline phase developed in the coarse glass sample.

The enthalpic relaxation process observed in Fig. 3 is characteristic of both annealed glasses and melts that are cooled using slow cooling rates [33] and [34]. When a glass spends enough time at temperatures that are relatively close to the $\mathrm{T}_{\mathrm{g}}$ (by either annealing or slow cooling rates), their molecules may have enough energy to cause some rearrangement in the amorphous structure. Therefore, this endothermic process is related to the energy required by the annealed glass to recover its previous internal structure before continuing with the devitrification process that occurs during heating. Both fine $(<63 \mu \mathrm{m})$ and coarse DSC curves show a well-defined exothermic peak that corresponds to a crystallisation process. However, the fine sample shows the crystallisation process occurring at lower temperatures and with higher intensity than the coarse sample, which indicates that both the surface and bulk crystallisation mechanisms coexist, although the surface crystallisation is predominant over the bulk crystallisation mechanism.

The optimum nucleation parameters (temperature an time) for $\mathrm{R}$ glass are $675^{\circ} \mathrm{C}$ and $80 \mathrm{~min}$, respectively, as determined from Fig. 5 and Fig. 6 . The formation of the maximum number of nuclei from the parent glass will occur under the optimum nucleation treatment and additional new nuclei will not be formed during heating. The calculated optimum nucleation temperature $\left(675^{\circ} \mathrm{C}\right)$ is higher than the $\mathrm{T}_{\mathrm{g}}\left(647^{\circ} \mathrm{C}\right)$, which, according to Zanotto [35] and $\mathrm{Hu}$ and Tsai [36], indicates that the process mainly occurs through volume crystallisation where the nuclei are homogeneously distributed throughout the bulk glass. Nevertheless, Fig. 3clearly shows a crystallisation peak in the DSC curve recorded from the fine sample $(<63 \mu \mathrm{m})$, which indicates that surface crystallisation is also possible in this glass. Another way to predict the crystallisation mechanism is through the reduced glass transition temperature $\left(T_{\mathrm{gr}}=\mathrm{T}_{\mathrm{g}} / \mathrm{T}_{\mathrm{m}}\right.$, where $\mathrm{T}_{\mathrm{g}}$ is the glass transition temperature and $\mathrm{T}_{\mathrm{m}}$ is the melting temperature, both values in 
J.M. Pérez, R. Casasola, J.Ma. Rincón, M. Romero, Nucleation and crystallisation kinetics of a Nafluorrichterite based glass by differential scanning calorimetry (DSC). Journal of Non-Crystalline Solids Volume 358, Issue 20, 1 October 2012, Pages 2741-2748; doi:10.1016/j.jnoncrysol.2012.05.047

Kelvin). According to James [37] and Zanotto [35] and [38], glasses that show a $\mathrm{T}_{\mathrm{gr}}>0.58-0.60$ only exhibit surface crystallisation that is mostly heterogeneous, whereas a $\mathrm{T}_{\mathrm{gr}}<0.58-0.60$ indicates homogeneous volume nucleation. The calculated values of $\mathrm{T}_{\mathrm{gr}}$ from Fig. 3 are 0.64 and 0.63 for the fine and coarse samples, respectively, which indicates that this glass presents heterogeneous nucleation (surface crystallisation). Considering both results, they indicate that both crystallisation mechanisms, volume and surface, simultaneously occur in the $\mathrm{R}$ glass. This occurrence is confirmed when the crystallisation sequence that occurs during the devitrification process of the $\mathrm{R}$ glass is observed (Fig. 7). During early stages of the devitrification process (Fig. 7a), the surface crystallisation mechanism is predominant. The crystal growth starts at the glass surface, resulting in the formation of a crystalline shell $(\approx 110 \mu \mathrm{m})$ that entirely covers the glass sample, while crystallisation is not observed in the interior. As the temperature increases (Fig. 7b), the surface growth continues to be prevalent and the depth of the crystallisation shell increases $(\approx 225 \mu \mathrm{m})$. However, at a certain moment, the energy of the system is enough to start bulk crystallisation and spherulitic crystals $(\approx 300 \mu \mathrm{m})$ begin to grow and are distributed uniformly throughout the entire volume of the glass sample (Fig. 7c). At this point, the crystallisation mechanism changes and volume crystallisation becomes predominant over surface crystallisation (Fig. 7d,e) even though the crystallisation shell continues to grow $(\approx 550 \mu \mathrm{m})$. Increasing the heating temperature results in a further development of the number and size $(\approx 1000 \mu \mathrm{m})$ of spherulitic crystals. Finally, the crystallisation progress leads to an enlargement of both the crystalline shell $(\approx 920 \mu \mathrm{m})$ and spherulites $(\approx 1200 \mu \mathrm{m})$, which come into contact with each other and with the crystallisation shell (Fig. 7f). Therefore, the residual glass phase is constrained to the spherulite-spherulite and spherulite-shell interphases and the crystal growth is sterically hindered.

The activation energy for the crystallisation determined using the Kissinger method (Fig. 8) was 440 and $401 \mathrm{~kJ} / \mathrm{mol}$ for the fine and coarse samples, respectively. The $\mathrm{E}_{\mathrm{a}}$ for the crystallisation of the fine glass sample is approximately $10 \%$ higher than the corresponding value for the monolithic glass. The difference in the values of the activation energy could explain the difference that was previously observed in the degree of crystallisation of these glass samples following thermal treatment at temperatures that are slightly above the temperature at the maximum of their respective crystallisation peaks (Fig. 3). The higher the activation energy, the greater the energy required to start the crystallisation process. As a result, after $60 \mathrm{~min}$ of thermal treatment, the fine glass sample is less crystallised and shows a higher amount of residual glass than the monolithic glass sample that has lower activation energy.

The average of the $\mathrm{n}$ parameter that was obtained by applying the Ozawa (Eq. $\underline{5}$ ) and Malek (Eq. $\underline{6}$ ) approximations and the Malek equation (Eq. $\underline{7}$ ) is approximately 3 (Table 2), indicating 
J.M. Pérez, R. Casasola, J.Ma. Rincón, M. Romero, Nucleation and crystallisation kinetics of a Na-

a three-dimensional growth of crystals during the glass crystallisation process. In the present study, it was assumed that no new nuclei are developed far away from the optimum nucleation point $\left(\mathrm{T}_{\mathrm{N}}, \mathrm{t}_{\mathrm{N}}\right)$. To contrast this assumption, the Matusita and Sakka method has been applied to the kinetic results. From the values of $n$ and $E_{a}$ obtained from the Kissinger method, the $m$ value determined by applying Eq. (4) was $3.10 \pm 0.17$. The similarity of the $n$ and $m$ values confirms that no new nuclei are formed during crystallisation. The mechanism that is fixed for $\mathrm{n}=\mathrm{m}=3$ is a three-dimensional growth of crystals.

The variation of $\mathrm{E}_{\mathrm{a} \alpha}$ with the degree of conversion, $\alpha$, as determined with the KAS isoconversional method (Fig. 10) depicts three reaction steps during the crystallisation process. The initial increase of $E_{a \alpha}$ indicates the existence of parallel reactions, whereas the constant value of $\mathrm{E}_{\mathrm{a} \alpha}$ during the majority of the crystallisation process indicates that one mechanism primarily governs the reaction over this interval. Finally, the decreasing of $E_{a \alpha}$ at higher degrees of conversion likely corresponds to a change in the crystallisation mechanism from a kinetic to a diffusion regime [39].

The three steps revealed from the isoconversional method can be correlated with the crystallisation sequence shown in Fig. 7. During the first stage $(\alpha<0.2)$, both the surface and bulk crystallisation mechanism occur simultaneously (Fig. 7a-c), whereas in the interval $\alpha=0.2-0.8$, bulk crystallisation prevails over surface crystallisation and governs the devitrification process (Fig. 7d-e). Finally, at higher degrees of conversion $(\alpha>0.8)$, the crystal growth is sterically hindered (Fig. 7f) and $\mathrm{E}_{\mathrm{aa}}$ decreases.

The accuracy of the proposed crystallisation mechanism $(n=3)$ is corroborated by applying the Pérez-Maqueda et al. The lines corresponding to the plot of the $A_{3}$ model (Fig. 11) fit a straight line, indicating that the crystallisation process proceeds through a three dimensional growth of crystals. The activation energy calculated from the slope of the lines is $394 \pm 2 \mathrm{~kJ} \mathrm{~mol}^{-1}$, which is in agreement with that obtained from the Kissinger and KAS methods.

\section{Conclusions}

The crystallisation process of a Na-fluorrichterite glass (designed $\mathrm{R}$ glass) was investigated by means of DSC, FESEM and XRD methods. The optimum nucleation parameters (temperature and time) were also determined using DSC. The crystallisation mechanism was studied by different methods, namely, non-isothermal (Kissinger and Matusita and Sakka methods) and isoconversional methods (Kissinger-Akahira-Sunose). The Avrami parameter, $\mathrm{n}$, was determined from three different approaches: Ozawa approximation, Malek approximation 
J.M. Pérez, R. Casasola, J.Ma. Rincón, M. Romero, Nucleation and crystallisation kinetics of a Na-

and Malek equation. The Pérez-Maqueda et al. criterion was applied to check the accuracy of the calculated n parameter. From the presented results, the following conclusions can be drawn:

- The optimum nucleation temperature and time were determined to be $675^{\circ} \mathrm{C}$ and $80 \mathrm{~min}$, respectively.

- The optimum nucleation temperature $\left(675^{\circ} \mathrm{C}\right)$ is higher than the $\mathrm{T}_{\mathrm{g}}\left(647^{\circ} \mathrm{C}\right)$, indicating that the crystallisation process takes place mainly through volume crystallisation. However, the reduced glass transition temperatures $\left(\mathrm{T}_{\mathrm{gr}}\right)$ are 0.64 and 0.63 for the fine and coarse samples, respectively, which indicates that the $\mathrm{R}$ glass presents heterogeneous nucleation (surface crystallisation). Considering both results, they indicate that both surface and bulk crystallisation mechanisms coexist during the crystallisation process.

- The activation energy of the crystallisation process as determined using the Kissinger method on monolithic glass samples is $401 \mathrm{~kJ} / \mathrm{mol}$, which is in good agreement with the values of 398 and $394 \mathrm{~kJ} / \mathrm{mol}$ determined from the KAS method and Pérez-Maqueda et al. criterion, respectively.

- The average of the $\mathrm{n}$ parameter obtained through three different approaches is approximately 3 , indicating three-dimensional growth of crystals during the crystallisation of the $\mathrm{R}$ glass.

- The KAS isoconversional method showed three steps during the crystallisation process: an increase in $\mathrm{E}_{\mathrm{a} \alpha}$ at lower degrees of conversion that corresponds to a parallel crystallisation mechanism (surface and bulk); constant $\mathrm{E}_{\mathrm{a} \alpha}$ in the interval $\alpha=0.2-0.8$, which is indicative of the prevalence of bulk crystallisation over surface crystallisation; and finally, a decrease in the activation energy at higher degrees of conversion indicates that the crystal growth is sterically hindered.

- The crystallisation of the $\mathrm{R}$ glass leads to a multiphase glass-ceramic material consisting of diopside $\left(\mathrm{CaMgSi}_{2} \mathrm{O}_{6}\right)$, fluorrichterite $\left(\mathrm{Na}_{2} \mathrm{CaMg}_{5} \mathrm{Si}_{8} \mathrm{O}_{22} \mathrm{~F}_{2}\right)$ and a magnesium silicate as forsterite $\left(\mathrm{Mg}_{2} \mathrm{SiO}_{4}\right)$ or enstatite $\left(\mathrm{MgSiO}_{3}\right)$ as crystalline phases together with a residual glassy phase.

- The glass particle size influences the development of crystalline phases. Fluorrichterite is the main crystalline phase developed in a coarse monolithic sample, while diopside mainly results during the crystallisation of a fine $(<100 \mu \mathrm{m})$ sample. 
J.M. Pérez, R. Casasola, J.Ma. Rincón, M. Romero, Nucleation and crystallisation kinetics of a Na-

fluorrichterite based glass by differential scanning calorimetry (DSC). Journal of Non-Crystalline Solids

Volume 358, Issue 20, 1 October 2012, Pages 2741-2748; doi:10.1016/j.jnoncrysol.2012.05.047

\section{Acknowledgements}

The authors would like to acknowledge Mrs. P. Díaz for the technical support of the experimental work. R. Casasola and J.M. Pérez express their gratitude to the Spanish National Research Council (CSIC) for their contract through the JAE Programme (JAEPre-08-00456 and JAEDoc-08-00362, respectively), co-financed by the European Social Fund. The financial support through the project MAT2006-05977 is also recognised.

\section{References}

[1] W. Hölland, G. Beall. Glass-Ceramic Technology. (second ed.)The American Ceramic Society, Ohio (2002)

[2] J.M.F. Navarro. El vidrio. (third ed.)Consejo Superior de Investigaciones Científicas, Madrid (2003)

[3] G.H. Beall. J. Non-Cryst. Solids, 129 (1991), pp. 163-173

[4] A.A. Omar, A.W.A. El-Shennawi, E.M. Hamzawi. Key Eng. Mater., 132-136 (1997), pp. 836-839

[5] M. Mirsaneh, I.M. Reaney, P.F. James. Phys. Chem. Glasses, 43C (2002), pp. 317-320

[6] A.W.A. El-Shennawi, A.A. Omar, E.M.A. Hamzawy. M.K. Choudhary, N.T. Huff, C.H. Drummond (Eds.), Proceedings of the 18th International Congress on Glass, American Ceramic Society, Westerville, OH (1998)

[7] I.L. Denry, J.A. Holloway. J. Biomed. Mater. Res., 53 (2000), pp. 289-296

[8] I.L. Denry, J.A. Holloway. J. Biomed. Mater. Res., 63 (2002), pp. 48-52

[9] E.M.A. Hamzawy, C. Leonelly, G.C. Pellacani. Glass Technol., 44 (2003), pp. 167-172

[10] E.M.A. Hamzawy, C. Leonelli. Glass Technol., 46 (2005), pp. 281-286

[11] E.M.A. Hamzawy, S.A.M. Abdel-Hameed. Ceram. Int., 35 (2009), pp. 2139-2144 
J.M. Pérez, R. Casasola, J.Ma. Rincón, M. Romero, Nucleation and crystallisation kinetics of a Na-

[12] M. Mirsaneh, I.M. Reaney, P.F. James, P.V. Hatton. J. Am. Ceram. Soc., 89 (2006), pp. $587-595$

[13] M. Mirsaneh, I.M. Reaney, P.V. Hatton, P.F. James. J. Am. Ceram. Soc., 87 (2004), pp. 240-246

[14] M. Mirsaneh, I.M. Reaney, P.V. Hatton, S. Bhakta, P.F. James. J. Non-Cryst. Solids, 354 (2008), pp. 3362-3368

[15] S. Bhakta, K. Pattanayak, H. Takadama, T. Kokubo, C.A. Miller, M. Mirsaneh, I.M. Reaney, I. Brook, R. van Noort, P.V. Hatton. J. Mater. Sci. Mater. Med., 21 (2010), pp. 29792988

[16] S. Bhakta, K.H. Gillingham, M. Mirsaneh, C.A. Miller, I.M. Reaney, I. Brook, R. van Noort, P.V. Hatton. J. Mater. Sci. Mater. Med., 22 (2011), pp. 2065-2070

[17] K.H.G. Ashbee. J. Mater. Sci., 10 (1975), pp. 911-917

[18] R. Keding, D. Stachel, C. Rüssel. J. Non-Cryst. Solids, 283 (2001), pp. 137-143

[19] Power Diffraction File Release 2000, Data Sets 1-50 plus 70-88 PDF $\square$, JCPDSInternational Centre for Diffraction Data. http://icdd.com

[20] M. Avrami. J. Chem. Phys., 7 (1939), pp. 1103-1113

[21] M. Avrami. J. Chem. Phys., 8 (1940), pp. 212-224

[22] M. Avrami J. Chem. Phys., 9 (1941), pp. 177-183

[23] H.E. Kissinger. Anal. Chem., 29 (1957), pp. 1702-1706

[24] K. Matusita, S. Sakka. J. Non-Cryst. Solids, 38 (1980), pp. 741-746

[25] T. Ozawa. Polymer, 12 (1971), pp. 150-158

[26] J. Málek.Thermochim. Acta, 355 (2000), pp. 239-253

[27] P. Murray, J. White. Trans. Br. Ceram. Soc., 54 (1955), pp. 151-187

[28] T. Akahira, T. Sunose Res. Rep. Chiba Inst. Technol., 16 (1971), pp. 22-31 
J.M. Pérez, R. Casasola, J.Ma. Rincón, M. Romero, Nucleation and crystallisation kinetics of a Na-

fluorrichterite based glass by differential scanning calorimetry (DSC). Journal of Non-Crystalline Solids

Volume 358, Issue 20, 1 October 2012, Pages 2741-2748; doi:10.1016/j.jnoncrysol.2012.05.047

[29] L.A. Pérez-Maqueda, J.M. Criado, F.G. Gotor, J. Malek. J. Phys. Chem. A, 106 (2002), pp. $2862-2868$

[30] O.C. Mocioiu, M. Zaharescu, G. Jitianu, P. Budrugeac. J. Therm. Anal. Calorim., 86 (2006), pp. 429-436

[31] A. Cadenato, J.M. Morancho, X. Fernández-Francos, J.M. Salla, X. Ramis. J. Therm. Anal. Calorim., 89 (2007), pp. 233-244

[32] B. Jankovic, B. Adnadevic, S. Mentus. Thermochim. Acta, 456 (2007), pp. 48-55

[33] I.W. Donald, B.L. Metcalfe. J. Non-Cryst. Solids, 348 (2004), pp. 118-122

[34] A.A. Francis, R.D. Rawlings, R. Sweeney, A.R. Boccaccini. J. Non-Cryst. Solids, 333 (2004), pp. 187-193

[35] E.D. Zanotto. J. Non-Cryst. Solids, 89 (1987), pp. 361-370

[36] Y. Hu, H.T. Tsai. J. Mater. Sci., 36 (2001), pp. 123-129

[37] P.F. James. M.H. Lewis (Ed.), Glasses and Glass-Ceramics, Chapman and Hall, London (1989), pp. 59-105

[38] E.D. Zanotto, M.C. Weinberg. Phys. Chem. Glasses, 30 (1989), pp. 186-192

[39] T. Ozawa. Bull. Chem. Soc. Jpn., 38 (1965), pp. 1881-1886 